\title{
CORONARY ARTERY ECTASIA; PREVALENCE AND CLINICAL CHARACTERISTICS: EXPERIENCE FROM A SINGLE CARDIAC CENTER
}

\footnotetext{
1. MBBS, FCPS (Cardiology) FACC, DIP CARD (PB) Associate Professor/ Head of Cardiology Department Faisalabad Institute of Cardiology, Faisalabad.

2. MBBS, FCPS (Cardiology) Assistant Professor of Cardiology/ Head of Cardiology Department University Medical \& Dental College/ Madina Teaching Hospital, Faisalabad.

3. MBBS, FCPS (Cardiology) Assistant Professor of Cardiology Faisalabad Institute of Cardiology, Faisalabad.
}

Correspondence Address: Dr. Liaqat Ali

Associate Professor/

Head of Cardiology Department

Faisalabad Institute of Cardiology,

Faisalabad.

hudadr1@hotmail.com

Article received on: 05/02/2017

Accepted for publication: 20/03/2017

Received after proof reading: 06/04/2017

\section{Dr. Liaqat Ali ${ }^{1}$, Dr. Naeem Asghar², Dr. Muhammad Yasir ${ }^{3}$}

\begin{abstract}
Background: Coronary artery ectasia (CAE) is well-recognized but relatively uncommon finding during diagnostic coronary angiography. Coronary artery ectasia is defined as a segment of coronary artery that is 1.5 times more dilated in diameter than the nearby segments. Its clinical presentations are unstable angina, coronary vasospasm, and acute myocardial infarction. Objectives: To determine the clinical characteristics, presentation and treatment in patients with documented coronary artery ectasia in a single Cardiac Centre at Faisalabad City Pakistan. Study Design: Retrospective descriptive study. Materials and Methods: This was a single center retrospective, descriptive study. Patients of either gender with age 21-70 years who had coronary angiography at Faisalabad Institute of Cardiology Faisalabad were included in the study. Coronary angiograms performed from April 2013 to December 2016 were reviewed. Patients fulfilling inclusion and exclusion criteria were enrolled. Clinical and angiographic profiles of the patients having coronary ectasia were retrieved from hospital record. Clinical profile included: age, gender and cardiovascular risk factors. Angiographic profile; prevalence of coronary ectasia, type of ectasia, associated obstructive disease and coronary vessel involved were noted. Results: Total 22235 patients under went coronary angiography from April 2013 to December 2016 at Faisalabad Institute of Cardiology Faisalabad. Out of 22235, 16913(76\%) were male and 5322(24\%) were female. Coronary artery ectasia (CAE) was observed in 1044(4.7\%). Out of 1044, $931(89 \%)$ were male and $113(10.9 \%)$ were female patients. Mean age of study population was $49.5 \pm 11.8$ years. $368(31.97 \%)$ patients with CAE were in age group of 51-60 years followed by age group $41-50$ years. 672 (64.36\%) were hypertensive, $433(41.7 \%)$ were diabetics, smoker were 574(54.98\%). 442(42.33\%) patients presented with ST elevation MI. 750 (71.84\%) patient had mild Ectasia, 155 (34.87\%) were suffering from severe coronary Ectasia. 364 (34.87\%) patients had associated obstructive coronary artery disease. LAD was most commonly involved vessel in $392(37.50 \%)$ followed by right coronary artery in $323(30.94 \%)$. Type I ectasia was documented in $34.92 \%$. Conclusions: In our study prevalence of CAE was $4.7 \%$. CAE was more common in male, hypertensive, smokers and patients with Hyperlipedemia. Most common pattern of CAE was Type I and isolated ectasia without coronary artery obstruction. Left anterior descending artery was the most commonly involved vessel in ectasia followed by RCA.
\end{abstract}

Key words: $\quad$ Ectasia, Angina, Infarction, Coronary artery.

Article Citation: Ali L, Asghar N, Yasir M. Coronary artery ectasia; prevalence and clinical characteristics: experience from a single cardiac center. Professional Med J 2017;24(4):545-553. DOI: 10.17957/TPMJ/17.3930

\section{INTRODUCTION}

Coronary artery ectasia (CAE) is relatively uncommon finding encountered during diagnostic coronary angiogram but it has been observed by cardiologists for more than two centuries.$^{1-3} \mathrm{CAE}$ is documented in $3-8 \%$ of patients undergoing coronary angiography and in $0.22 \%$ to $1.4 \%$ of autopsy series. CAE is defined as inappropriate dilation of the coronary arteries exceeding the largest diameter of an adjacent normal vessel more than 1.5 fold..$^{1,4}$ It can be either diffuse affecting the entire length of a coronary artery, or localized. The term ectasia refers to diffuse dilation of a coronary artery while focal dilation is known as coronary aneurysm. ${ }^{5}$

Several mechanisms are involved in the pathophysiology of CAE. In more than 50\% of patients, most commonly CAE is related to atherosclerotic coronary artery disease (CAD) 
and therefore it is also considered as a variant of coronary atherosclerosis. Atherosclerosis also explains the coexistent obstructive coronary artery disease (CAD) with coronary artery ectasia in the great majority of patients. However in $10 \%$ to $20 \%$ cases, CAE is related to inflammatory diseases. ${ }^{1}$ In various studies it was documented that there is strong association of $\mathrm{CAE}$ with connective tissue disorders like scleroderma and EhlersDanlos syndrome. ${ }^{6}$ Kawasaki disease, syphilitic aortitis and ANCA- related vasculitis was noted in patients with $\mathrm{CAE} .{ }^{7} \mathrm{CAE}$ may be congenital in some patients. On IVUS it has confirmed that in coronary atherosclerosis arterial expansion and/ or shrinkage can be manifestations. Conventional risk factors associated with atherosclerosis are also related with coronary artery ectasia.

The lesions in CAE have same characteristics as coronary artery atherosclerosis and some hypothesis links these both diseases. In some previous studies, pathological characteristics of CAE were described and it has features of chronic inflammation along with foam cells loaded with lipid deposition and loss of muscle wall elasticity. ${ }^{8}$ The most probable mechanism that may involve in CAE is endothelium overstimulation by nitrous oxide (NO) or NO donors. In previous studies it was documented that NO production had increased viai NOS pathway in CAE. ${ }^{9}$

Daugherty et al. documented in his study a strong relationship between angiotension II and ventricular remodeling. ${ }^{10}$ Matrix metalloproteinase 2 is main enzyme which causes extracellular matrix degradation and play role in vascular remodeling. In patients with CAE, different studies have demonstrated an imbalance between metalloproteinase and endogenous tissue inhibitors. ${ }^{11}$

The Coronary artery ectasia produces sluggish blood flow in coronary vessels resulting in thrombus formation, vasospasm and spontaneous dissection leading to acute coronary syndrome. Regarding course of CAE, $15 \%$ patients have benign course, but features of old myocardial infarction were observed in $39 \%$ patients. ${ }^{1}$
The purpose of current study was to update about the prevalence of coronary artery ectasia along with its presentation, treatment options and to evaluate the clinical factors related to coronary ectasia and angiographic features of patients.

\section{MATERIALS AND METHODS}

This study was conducted at Faisalabad Institute of Cardiology Faisalabad which is among the major tertiary care cardiac centers in Pakistan. We retrospectively analyzed coronary angiographies of all patients who were either admitted with ACS and their coronary angiography was performed or was referred to our center for angiography from other centers from April 2013 to December 2016 and subsequently CAE was diagnosed and who fulfill the inclusion and exclusion criteria. Coronary ectasia was defined as, dilation of coronary artery 1.5 times or more in diameter than the nearby segments in a part or whole of the coronary artery, with or without obstructive coronary artery disease. ${ }^{12}$

\section{Study Design}

It was a single centre retrospective descriptive study.

\section{Sampling technique}

Non-probability, purposive sampling technique was used

\section{Inclusion Criteria}

Following patients were included in the study:

- Any patient of age 21-70 years of either gender.

- Patients with typical chest pain more than 20 minutes, ischemic in nature having unstable pattern, pain at rest, new onset of pain, increased severity or frequency of angina (accelerating angina).

- Patients with a diagnosis of ACS (ST elevation or non-ST) undergoing coronary angiography having CAE on final report.

- Fully assessable angiographic data.

\section{Exclusion Criteria}

- Previous $\mathrm{H} / \mathrm{O} \mathrm{PCl}$.

- H/O previous CABG.

- Patients with any valvular or structural heart 
disease.

- Patients with cardiomyopathy.

Total 22235 patients attended Faisalabad Institute of Cardiology, Faisalabad for coronary angiography. They were either admitted with ACS or came with stable angina or were referred for angiography from other centers. Findings of 12 leads ECG of all patients were noted to observe any ST segment elevation or depression. Findings of transthorasic echocardiography were documented for any Valvular or structural heart disease. $\mathrm{H} / \mathrm{O}$ risk factors for CAD like history of hypertension, diabetes mellitus, family $\mathrm{H} / \mathrm{O}$ ischemic heart disease and hyperlipidemia was retrieved from the patient's record. Diabetes was identified on the basis of hospital record or if patient was taking anti diabetic medications (Insulin/ OHGA) or fasting blood sugar was $\geq$ $126 \mathrm{mg} / \mathrm{dl}$. Patient was labeled hypertensive on the basis of hospital record or if patient was taking antihypertensive medications or his/her BP was documented $\geq 140 / 90 \mathrm{mmHg}$ in medical chart. Dyslipidemia was defined if total serum cholesterol was $\geq 180 \mathrm{mg} / \mathrm{dl}$ in fasting state or patient was on statin therapy for it. In all patients who underwent angiography, Lab. investigations including complete blood count, fasting blood sugar, fasting lipid profile, blood urea and serum creatinine levels were noted from hospital data base. Values of cardiac markers (cardiac enzymes/ Troponin I level) were documented of each patient. Patients were considered smokers if still they were smoking (Huqa and/ or Cigarettes) at the time of angiography. Body mass index (BMI) was noted from the record. On the basis of ECG analysis and hospital record it was documented that whether the patient was admitted with ST/ non ST elevation ACS.

In all patients, Coronary angiography reports were reviewed by two independent observers for coronary ectasia or aneurysm along with any obstructive CAD. Left main stem disease was considered significant if stenosis was $\geq 50 \%$ and disease was considered significant if stenosis was $\geq 70 \%$ in other vessels. Markis classification of coronary artery ectasia was used to describe the type of ectasia.

Type I Involvement of two or more vessels in diffuse ectasia.

Type II If one vessel has diffuse Ectasia and other vessel has localized ectasia.

Type III Involvement of only one vessel having diffuse ectasia.

Type IV If only one vessel is involved and has segmental or localized ectasia.

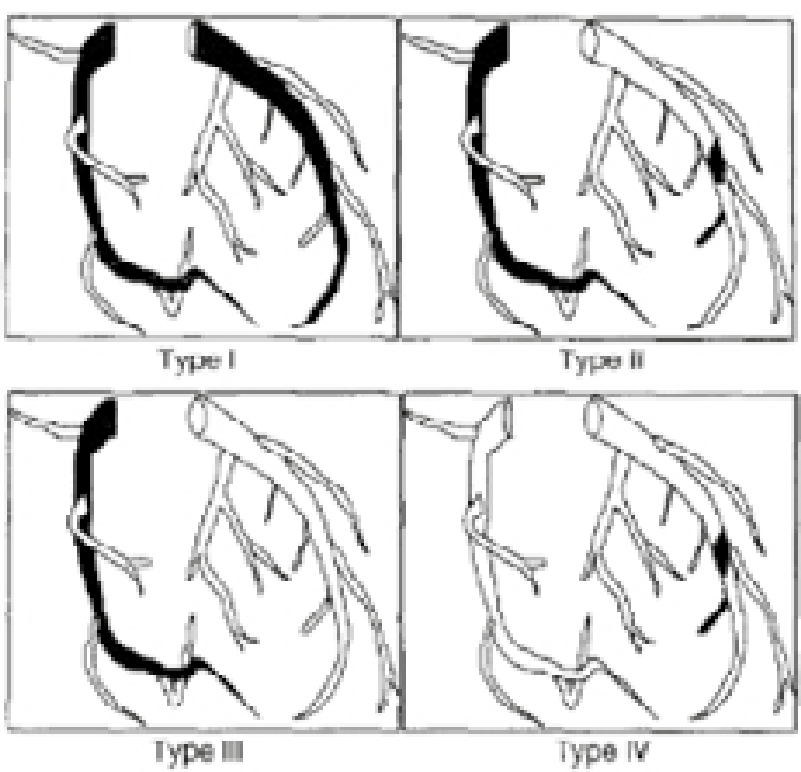

STATISTICAL ANALYSIS

All the data was analyzed by SPSS (Statistical Package for Social Sciences) Version 23 for Windows. Categorical variables like gender, hypertension, Diabetes, hyperlipidemia, smoking, Troponin-I levels, cardiac enzymes and angiographic findings were documented by frequency and percentage and continues variables were presented as means ${ }^{ \pm} \mathrm{SD}$ (Standard Deviation). Effect modifiers like age, genders, hypertension, diabetes, hyperlipidemia and smoking were stratified. To control its effect on outcome variable, post stratification chi-square test was applied. $\mathrm{P}$ value $\leq 0.05$ was taken as significant. All tests applied were two tailed.

\section{RESULTS}

Overall 22235 patients under went coronary angiography at our center from April 2013 to December 2016. 16913(76\%) were male 
and 5322(24\%) were female. 1044(4.7\%) had coronary ectasia (CAE), 931(89\%) were male and $113(10.9 \%)$ were female patients. (Table-I). Mean age of study population was $49.5 \pm 11.8$ years (range 21-70 years). Considering effect of age, maximum patients 368(31.97\%) who were suffering from CAE were in age group 51-60 years followed by age group 41-50 years. Between age group 51-60 years, there were not only maximum sufferer in ectasiabut disease was also moresevere in this age group in 60(15.54\%) patients followed by in age group 41-50, 44(13.37\%) patients TableII \& IV. LAD and RCA were two vessels which were involved most commonly 137(35.49\%) and $133(34.26 \%)$ respectively in disease in this age group Table IV. Only $2.2 \%$ patients having CAE were in age group of 21-30 years. 672 (64.36\%) were hypertensive, $433(41.7 \%)$ were diabetics, smoker were 574(54.98\%) and dyslipidemia was documented in 514(49.23\%) patients Table II \& Figure-1. Family history for IHD was positive in $244(23.37 \%)$. Obesity was documented in $310(29.69 \%)$ patients. $641(61.39 \%)$ patients with ectasia had positive Trop I. 442(42.33\%) presented with ST elevation MI, 286(27.39\%) with non ST elevation MI, 142 (13.60\%) came with unstable angina (Table-II).

\begin{tabular}{|l|c|c|c|}
\hline & Patients & Male & Female \\
\hline $\begin{array}{l}\text { Overall } \\
\text { patients }\end{array}$ & 22235 & $16913(76 \%)$ & $5322(24 \%)$ \\
\hline $\begin{array}{l}\text { Patients with } \\
\text { Ectasia }\end{array}$ & 1044 & $931(89 \%)$ & $113(10.9 \%)$ \\
\hline \begin{tabular}{l} 
Table-I. Results of 4 years of coronary angiography. \\
\hline
\end{tabular}
\end{tabular}

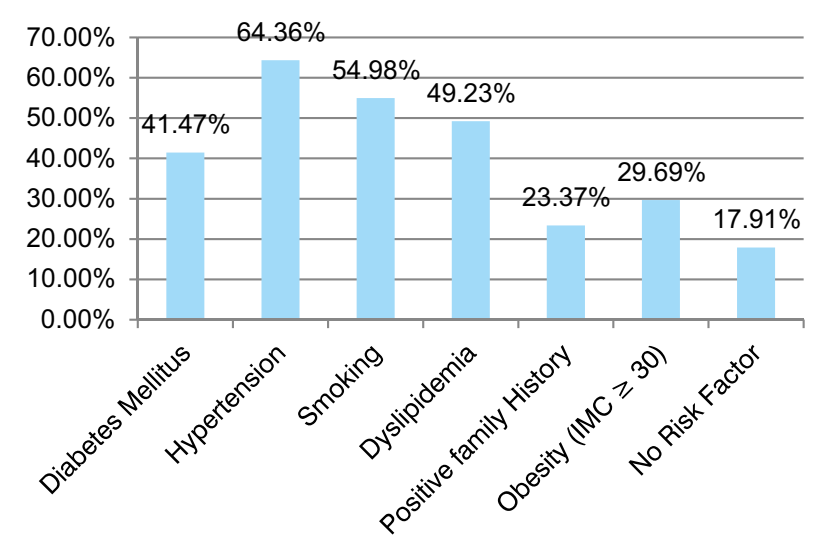

Figure-1. Risk factors for coronary ectasia

\begin{tabular}{|l|c|c|}
\hline \multicolumn{1}{|c|}{ Characteristics } & Number & Percentage \\
\hline Age (Years) & & \\
\hline $21-30$ & 23 & $2.20 \%$ \\
\hline $31-40$ & 142 & $13.60 \%$ \\
\hline $41-50$ & 329 & $31.51 \%$ \\
\hline $51-60$ & 386 & $36.97 \%$ \\
$61-70$ & 164 & $15.70 \%$ \\
\hline Gender & & \\
\hline Male & 931 & $89 \%$ \\
\hline Female & 113 & $10.9 \%$ \\
\hline Diabetes Mellitus & 433 & $41.47 \%$ \\
\hline Hypertension & 672 & $64.36 \%$ \\
\hline Smoking & 574 & $54.98 \%$ \\
\hline Dyslipidemia & 514 & $49.23 \%$ \\
\hline Positive family History & 244 & $23.37 \%$ \\
\hline Obesity (IMC $\geq 30)$ & 310 & $29.69 \%$ \\
\hline No Risk Factor & 187 & $17.91 \%$ \\
\hline Troponin I Positive & 641 & $61.39 \%$ \\
\hline Mode of presentation & & \\
\hline STEMI & 442 & $42.33 \%$ \\
\hline NSTEMI & 286 & $27.39 \%$ \\
\hline USA & 142 & $13.60 \%$ \\
\hline Others & 174 & $16.66 \%$ \\
\hline ECTASIA & & \\
\hline Mild & 750 & $71.83 \%$ \\
\hline Moderate & 139 & $13.31 \%$ \\
\hline Severe & 155 & $14.84 \%$ \\
\hline Ectasia with stenosis & 364 & $34.86 \%$ \\
\hline Ectasia without & 680 & $65.13 \%$ \\
\hline stenosis & 365 & $34.96 \%$ \\
\hline Type I Ectasia & 299 & $28.63 \%$ \\
\hline Type II Ectasia & 215 & $20.60 \%$ \\
\hline Type III Ectasia & 165 & $15.80 \%$ \\
\hline Type IV Ectasia & & \\
\hline \multicolumn{1}{|c|}{ Hospital Stay in Days(Mean) 5.31} & days $(5-9)$ \\
\hline \multicolumn{1}{|c|}{ Table-II. Baseline characteristics of } & patients \\
\hline & & \\
\hline
\end{tabular}

\begin{tabular}{|l|c|c|}
\hline \multicolumn{1}{|c|}{ Vessel Involved } & Number & Percentage \\
\hline Left main coronary artery & 29 & $2.78 \%$ \\
\hline Right coronary artery & 323 & $30.94 \%$ \\
\hline Left anterior descending artery & 392 & $37.55 \%$ \\
\hline Left Circumflex artery & 296 & $28.35 \%$ \\
\hline Ramus Intermedius & 4 & $0.38 \%$ \\
\hline Table-III. Distribution of patients according to vessel \\
involvement in ectasia
\end{tabular}

750 (71.84\%) patient had mild Ectasia, 139 (13.31\%) patient had moderate Ectasia, 155 (34.87\%) were suffering from severe coronary Ectasia (Table-II). 364 (34.87\%) patients had associated obstructive coronary artery disease. 


\begin{tabular}{|c|c|c|c|c|}
\hline \multirow{2}{*}{ Different Age Groups With Vessel Involved } & \multicolumn{3}{|c|}{ Ectasia } & \multirow[b]{2}{*}{ Grand Total } \\
\hline & Mild & Moderate & Severe & \\
\hline $21-30$ & 15 & 4 & 4 & 23 \\
\hline Left Anterior Descending Artery: & 6 & 1 & 2 & 9 \\
\hline Left Circumflex Artery: & 4 & 1 & & 5 \\
\hline Left Main Stem & 0 & 0 & 1 & 1 \\
\hline Right Coronary Artery: & 5 & 2 & 1 & 8 \\
\hline $31-40$ & 101 & 21 & 20 & 142 \\
\hline Left Anterior Descending Artery: & 42 & 11 & 7 & 60 \\
\hline Left Circumflex Artery: & 29 & 5 & 5 & 39 \\
\hline Left Main Stem: & 7 & 1 & & 8 \\
\hline Right Coronary Artery: & 23 & 4 & 7 & 35 \\
\hline $41-50$ & 254 & 31 & 44 & 329 \\
\hline Left Anterior Descending Artery: & 100 & 10 & 16 & 126 \\
\hline Left Circumflex Artery: & 79 & 7 & 8 & 94 \\
\hline Left Main Stem: & 4 & 1 & & 5 \\
\hline Ramus Intermedius: & & & 1 & 1 \\
\hline Right Coronary Artery: & 70 & 13 & 19 & 103 \\
\hline $51-60$ & 263 & 63 & 60 & 386 \\
\hline Left Anterior Descending Artery: & 94 & 18 & 25 & 137 \\
\hline Left Circumflex Artery: & 75 & 16 & 9 & 100 \\
\hline Left Main Stem: & 9 & 2 & 2 & 13 \\
\hline Ramus Intermedius: & 2 & & 1 & 3 \\
\hline Right Coronary Artery: & 83 & 27 & 23 & 133 \\
\hline $61-70$ & 117 & 20 & 27 & 164 \\
\hline Left Anterior Descending Artery: & 47 & 5 & 8 & 60 \\
\hline Left Circumflex Artery: & 39 & 7 & 11 & 57 \\
\hline Left Main Stem: & 2 & & & 2 \\
\hline Right Coronary Artery: & 29 & 8 & 8 & 45 \\
\hline Grand Total & 750 & 139 & 155 & 1044 \\
\hline Table-IV. Ec & in differe & groups & & \\
\hline Vessel Involved In CAE & Male & Female & & Grand Total \\
\hline Left Anterior Descending Artery & 345 & 47 & & 392 \\
\hline Right coronary artery & 299 & 25 & & 324 \\
\hline Left Circumflex Artery: & 261 & 34 & & 295 \\
\hline Left Main Stem: & 23 & 6 & & 29 \\
\hline Ramus Intermedius: & 3 & 1 & & 4 \\
\hline Grand Total & 931 & 113 & & 1044 \\
\hline
\end{tabular}

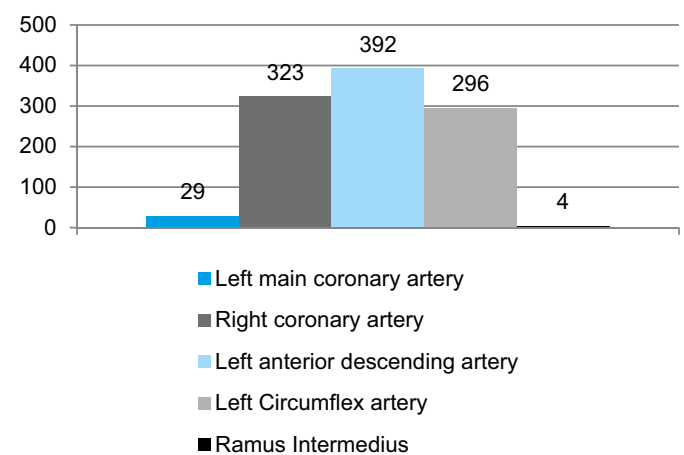

Figure-2. Coronary ectasia in different vessel
$680(65.1 \%)$ had no associated significant coronary artery disease. Regarding the types of ectasia, type I ectasia was most common and it was documented in 365(34.96\%) while in 299 (28.63\%) patient's type II ectasia was noted. In only $165(15.80 \%)$ patients type IV ectasia was documented (Table-II). Mean hospital stay was 5.1 days. In LAD ectasia was observed in 39 $(37.50 \%)$ patients followed by right coronary artery 323 (30.94\%), least involved vessel in coronary artery ectasia was Ramus Intermedius in $4(0.387 \%)$ Table-III \& Figure-2. Regarding effect 
of gender on disease pattern, in male LAD was involved in $345(88 \%)$ and in $47(11.99 \%)$ female patients. In male, ectasia in RCA was observed in $299(92.28 \%)$ and in female it was documented in 25(7.72\%) Table-V.

\section{DISCUSSION}

Coronary artery ectasia was documented by Morgagni for the first time. ${ }^{8}$ Coronary artery ectasia (CAE) is a well-recognized but relatively uncommon finding encountered during coronary angiogram with various patterns of presentation and prevalence. ${ }^{1-3}$ The gold standard investigation for the CAE remains the coronary angiogram. ${ }^{9}$ Intravascular ultrasound is an excellent tool to assess luminal size and characterize arterial wall changes and it differentiates correctly a true from a false aneurysm caused by plaque rupture. Recently, MDCT is also used as a non-invasive tool for the diagnosis of CAE.

A lot of studies and analysis have been conducted with aim to understand this entity. Atherosclerosis remained the major etiological factor in adults while Kawasaki disease is the most common cause in children or young adults. ${ }^{13}$ The specific causative mechanisms of abnormal dilatation of the lumen in CAE are essentially unknown. Current literature suggests that ectatic coronary arteries, even without the presence of coronary stenosis, are subject to thrombus formation, vasospasm, and spontaneous dissection. The prognosis of CAE depends directly on the severity of the concomitant coronary artery disease. CAE with obstructive coronary artery disease is a vicious condition because of its potential to cause several adverse cardiac events.

In our study prevalence of CAE was $4.7 \%$ which coincides with other international studies results. Leschka et al. conducted a study on 677 patients by using MDCT and he documented CAE in $3 \%$ of patients. ${ }^{14}$ In other studies incidence of CAE was documented $0.3 \%-4.9 \% .^{1-3}$ It was documented in various studies that on the distribution of ectasia there is no any additional effect of age. Sharma et al found in his study that nature of ectasia in young and old patients was not different. ${ }^{15}$ Results of current study coincide with other international studies in that pattern of CAE is almost same in different age groups. In our study most of the patients belonged to age group of 51 - 60 years and this is same age group which is more prone to CAD. Higher incidence of $\mathrm{CAE}$ was observed in male than female in the largest series of patients in CASS registry by Swaye et $\mathrm{al}^{3}$ and these results coincide with our results. Regarding risk factors for CAE, majority of the patients had same conventional major risk factors as were documented in patients with CAD having atherosclerosis which indicate that coronary ectasia is most commonly associated with atherosclerosis. Hypertension, smoking and dyslipidemia were the most common risk factors documented among patients of CAE in our study, however in different studies prevalence of different cardiovascular risk factors were different. ${ }^{3,16}$

It was documented in a previous study that in patients having familial hypercholesterolemia there is high incidence of CAE. ${ }^{17}$ In current study dyslipidemia was observed in 514(49.23\%) and hypertension was documented in 672(64.36\%) and these results coincide with other studies. ${ }^{18}$ It was described in various previous studies that there is a close association between aortic aneurysms and CEA. ${ }^{19}$

CAE is not a benign condition. Angina is the most common reported symptom of $\mathrm{CAE},{ }^{20}$ but in other studies STEMI, non-STEMI, arrhythmias, or sudden death were reported..$^{21}$ In current study 442(42.33\%)patients presented with AMI and only $142(13.60 \%)$ presented with UA. Regarding prognosis of patients with CAE the literature is unclear but in our study, only one patient death was reported $(0.095 \%)$.

According to Tunick et al. study results, discrete ectasia develops exclusively in the presence of tight stenosis ${ }^{22}$ but in our study 680(65.13\%) patients had ectasia without significant coexisting stenosis. In current study type I ectasia was the most common pattern observed in our population. Demopoulos and $\mathrm{H}$ arikrishnan observed in their studies that RCA was the most 
commonly involved vessel in ectasia followed by LCX and ectasia was observed in very little no of patients in LAD but in our study LAD was the main vessel involved in ectasia. In different previous studies it was observed that RCA showed diffuse nature of ectasia while it was of predominantly discrete form of ectasia in $L^{2} D^{23,24}$ and our results coincide with these studies.

Regarding the management protocol for CAE, there are no guidelines; all the recommendations are on experience. In our study all the patients were treated with dual antiplatelets and statins but still there are questions for optimum treatment of ectasia, anticoagulants' like Warfarin, aspirin, calcium channel and beta-blockers all are suggested treatments. ${ }^{25}$ To prove the treatment options for CAE, case-control studies must be carried out. Still there is some controversy regarding the use of oral anticoagulants for CAE. Oral anticoagulants were tested in a series of patients without any benefit in 2-5 years followups $^{23}$, so recommendation for anticoagulants must be reviewed in a larger cohorts study due to high risk of bleeding/hemorrhage with oral anticoagulants.

In our study most of the patients were discharged on DAP therapy (aspirin and clopidogrel). Use of beta-blockers and/or calcium channel blockers reduces the arterial flow so use of these drugs must be individualized for each patient. There are no specific recommendations for this strategy and the same applies to statins. ${ }^{26}$

\section{CONCLUSION}

In our study prevalence of CAE was similar to other international studies reported in the medical literature. The main clinical presentation was acute coronary syndrome such as STEMI, NSTEMI and USA. CAE was more common in male, hypertensive, smokers and patients with Hyperlipedemia. Most common pattern of CAE was Type I and isolated ectasia without coronary artery obstruction. Left anterior descending artery was the most commonly involved vessel in ectasia followed by right coronary artery, left circumflex and left main coronary artery. In most of the cases
$\mathrm{PCl}$ was not feasible in the affected artery due to diameter of the vessel. After an acute event has been controlled in patients with CAE, still there is no consensus regarding ongoing management of this disease.

\section{STUDY LIMITATIONS}

Our study was a retrospective single center study and there was no follow-up of patients. Secondly, our patient's record is not as good as international.

\section{ABBREVIATIONS}

- ACS: acute coronary syndrome.

- AMI: acute myocardial infarction.

- CAE: coronary artery ectasia.

- Cx: circumflex artery.

- iNOS: inducible nitric oxide synthase.

- LAD: left anterior descending artery.

- LMS: left main Stem.

- NO: nitric oxide.

- Non-STEMI: Non-ST elevation myocardial infarction.

- PCl: Percutaneous coronary intervention.

- RCA: right coronary artery.

- STEMI: ST elevation myocardial infarction.

- UA: unstable angina.

Copyright (C) 20 Mar, 2017.

\section{REFERENCES}

1. G.G. Hartnell, B.M. Parnell, R.B. Pridie, Coronary artery ectasia. Its prevalence and clinical significance in 4993 patients, British Heart Journal 54 (4) (1985) 392395.

2. V.L. Sorrell, M.J. Davis, A.A. Bove, Current knowledge and significance of coronary artery ectasia: a chronologic review of the literature, recommendations for treatment, possible etiologies, and future considerations, Clinical Cardiology 21 (3) (1998) 157-160.

3. P.S. Swaye, L.D. Fisher, P. Litwin, et al., Aneurysmal coronary artery disease, Circulation 67 (1) (1983) 134-138.

4. M. Syed, M. Lesch, Coronary artery aneurysm: a review, Progress in Cardiovascular Diseases 40 (1) (1997) 77-84.

5. S. Mavrogeni, Coronary artery ectasia: from diagnosis to treatment, Hellenic Journal of Cardiology: HJC 1/4 Hellenikekardiologikeepitheorese 51 (2) (2010) 158- 
163.

6. Mavrogeni S, Manoussakis MN, Karagiorga TC, Douskou M, Panagiotakos D, Bournia V, Cokkinos DV, Moutsopoulos HM. Detection of coronary artery lesions and myocardial necrosis by magnetic resonance in systemic necrotizing vasculitides. Arthritis Rheum. 2009; 61(8):1121-9.

7. José Manuel Ruiz-Morales, ${ }^{\star}$ Octavio González-Chon, ** Sandra María del Carmen García-López ${ }^{* *}$ Coronary artery ectasia prevalence and clinical characteristic experience from a single medical center Rev Invest Med Sur Mex, Octubre-Diciembre2013; 20 (4): 208-213

8. Virmani R, Robinowitz M, Atkinson JB, Forman MB, Silver MD, McAllister HA. Acquired coronary arterial aneurysms: an autopsy study of $\mathbf{5 2}$ patients. Hum Pathol 1986; 17: 575-83.

9. Sorrell VL. Origins of coronary artery ectasia. Lancet 1996; 20: 136-7.

10. Daugherty A, Manning MW, Cassis LA. Angiotensin II promotes atherosclerotic lesions and aneurysms in apolipoprotein E-deficient mice. J Clin Invest 2000; 105:1605-12.

11. Finkelstein A, Michowitz $Y$, Abashidze A, Miller $H$, Keren $\mathrm{G}$. Temporal association between circulating proteolytic, inflam-matory and neurohormonal markers in patients with coronary ectasia. Atherosclerosis 2005; 179(2): 353-9.

12. Syed $M$, Lesch $M$. Coronary artery aneurysm: a review. ProgCardiovasc Dis 1997; 40: 77-84.

13. M. Diaz-Zamudio, U. Bacilio-Perez, M.C. Herrera-Zarza, et al., Coronary artery aneurysms and ectasia: role of coronary CT angiography, Radiographics 29 (7) (2009) 1939-1954.

14. Leschka S. Stolzmann P, Scheffel H, Wildermuth S, Plass A, Genoni M, et al. Prevalence and morphology of coronary artery ectasia with dual-source CT coronary angiography. EurRadiol 2008; 18:2776-84.

15. Sharma SN, Kaul U, Sharma S, Wasiv HS, Manchanda SC, BahI VK, Talwar KK, Rajani M, Bhatia ML. Coronary arteriographic profile in young and old Indian patients with ischaemic heart disease: a comparative study. Indian Heart J 1990; 42:365-369.
16. M. Saglam, I. Barutcu, O. Karakaya, et al., Assessment of left ventricular functions in patients with isolated coronary artery ectasia by conventional and tissue Doppler imaging, Angiology 59 (3) (2008) 306-311.

17. Sudhir K, Ports TA, Amidon TM, Goldberger JJ, Bhushan $V$, Kane JP. Increased prevalence of coronary ectasia in hetero-zygous familial hypercholesterolemia. Circulation 1995; 91: 1375-80.

18. Cokkinos DV, Demopoulos VP, Voudris V, Manginas A, Cotileas P, Foussas SG. Coronary artery ectasia: aspects of fitness to fly. Eur Heart J 1999; 1: D53-D58.

19. Befeler B, Aranda JM, Embi A, Mullin FL, El-Sherif N, Lazzara R. Coronary artery aneurysms. Study of their etiology, clinical cour-se and effect on left ventricular function and prognosis. Am JMed 1977; 62: 597-607.

20. Akyurek O, Berkalp B, Sayin T, Kumbasar D, Kervancioglu C. Altered coronary flow properties in diffuse coronary artery ecta-sia. Am Heart J 2003; 145(1): 66-72.

21. Lahiri S, Sethi KK, Jain R, Sawhney JPS, Chopra VK. Coronary ectasia: Prevalence, clinical and angiographic characteristics (abstr). Indian Heart $\mathrm{J}$ 2002; 54(5): D37-D38.

22. Tunick PA, Slater J, Kronzon I, Glassman E. Discrete atherosclerotic coronaryartery aneurysms: a study of 20 patients. J Am CollCardiol 1990; 15: 279-282.

23. Demopoulos V, Olympios C, Fakiolas C, Pissimissis E, Economides N, Adamopoulou E, Foussas S, Cokkinos $D V$. The natural history of aneurysmal coronary artery disease. Heart 1997; 78: 136-141.

24. Sunder KR, Tharakan J, Titus T, Bhat Harikrishnan S, A, Sivasankaran S, Francis B. Coronary artery ectasia: angiographic, clinical profile and follow-up. Indian Heart J. 2000 Sep-Oct; 52(5):547-53.

25. Nagata K, Kawasaki T, Okamoto A, Okano A, Yoneyama $S$, Ito $K$, Katoh S. Effectiveness of an antiplatelet agent for coronary artery ectasia associated with silent myocardial is-chemia. Jpn Heart J 2001; 42(2): 249-54.

26. Swanton RH, Thomas MC, Coltart DJ, Jenkins BS, WebbPeploe MM, Williams B T. Coronary artery ectasia: a variant of occlusive coronary arteriosclerosis. British Heart J 1978; 393-400. 


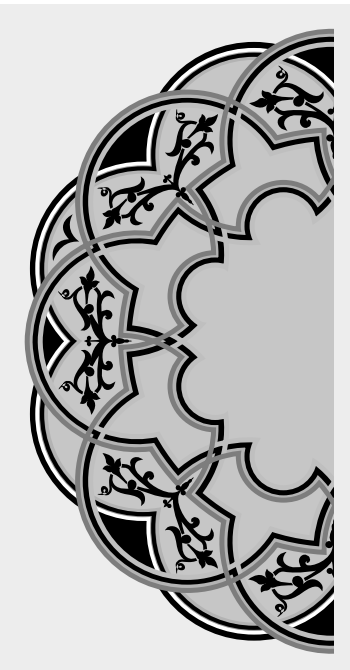

"You become what you believe."

\section{Unknown}

\section{AUTHORSHIP AND CONTRIBUTION DECLARATION}

\begin{tabular}{|c|c|c|c|}
\hline Sr. \# & Author-s Full Name & Contribution to the paper & Author $=\mathbf{s}$ Signature \\
\hline 1 & Dr. Liaqat Ali & Data collection & \\
\hline 2 & Dr. Naeem Asghar & Manuscript Writing & \\
\hline 3 & Dr. Muhammad Yasir & Data analysis, manuscript writing & \\
\hline
\end{tabular}

